\title{
Multigrade teachers' experiences and learning assessments on modular remote teaching during the COVID-19 pandemic
}

Chan, Joefrey R.

Philippine Normal University, Philippines

Araullo High School, Philippines (chan.jr@pnu.edu.ph)

Marasigan, Arlyne C.

Philippine Normal University, Philippines (marasigan.ac@pnu.edu.ph)

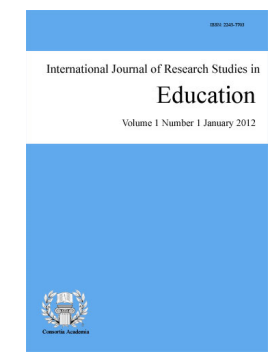

ISSN: $2243-7703$ Online ISSN: 2243-7711

OPEN ACCESS

Santander, Neil T.

DepEd, Quezon Province,Philippines (neil.santander@deped.gov.ph)

\section{Abstract}

The study explored multigrade teachers' experiences and learning assessments on modular remote teaching during the COVID-19 pandemic. Illustrative case study qualitative research was employed in data gathering. Results uncovered multigrade teachers' experiences and conduct of learning assessments which include: traversing arduous path where distribution and retrieval of modules are located; video lessons and supplementary reading materials were made to combat insufficient supply of learning materials and poor internet access; instances such as adversity in module distribution, erroneous modules, loss of interest among students, and resistant parents in fulfilling roles as support to their child's learning aggravated multigrade teachers' challenges; support of local government is significant but limited in the modular remote teaching; quality assured modules and stronger financial support would aid better modular remote teaching delivery; teacher-in-charge performs extra responsibility in doing the job of school head with teaching loads; and multigrade teachers intricately conduct learning assessments in response to community needs and adherence with the Department of Education order. It is recommended that education policy makers should review and re-assess budget allotments for modular remote teaching. Furthermore, improvement of quality-controlled modules and worksheets, prompt arrival and distribution of learning materials and provision of sufficient supply of references for multigrade teachers are highly recommended to cater better facilitation of modular remote teaching and learning assessments in times of pandemic.

Keywords: multigrade school; multigrade teachers; remote learning; learning assessment; COVID-19 Pandemic 


\section{Multigrade teachers' experiences and learning assessments on modular remote teaching during the COVID-19 pandemic}

\section{Introduction}

One of the priorities of each country from the different parts of the world is to enhance the outcomes of their education for the benefit of their economy. To make this into reality, one of the United Nation's agenda for world transformation to sustainable development for 2030 is to ensure quality education inclusively and with equity by promoting learning opportunities for all that is lifelong. However, the 2020 report on sustainable development goals of the United Nations highlighted that the COVID-19 pandemic worsen the crisis in education and further built-up inequalities that exist in accessing education. Moreover, the report also stressed that the education targets for 2030 is not on track despite of the progress. This is because the learning outcomes of youths and children together with their behavioral and social development is affected by the disruption of education. Furthermore, the COVID-19 pandemic's impact on closures of schools made many school administrators to opt for remote learning through virtual classrooms and this made further problems to students who lacks computer access and internet at home; are marginalized; and are low skilled in computer literacy (UN, 2020).

In line with the UN's sustainable development goals, the Philippine development plan for 2017-2022 also emphasized that opportunities for lifelong learning is expected to be made available for everyone by making facilities and curriculum more accessible and relevant respectively. It is also reported that there are disparities in some of the education sectors in the Philippines that are left behind that needs to be prioritized in improving the quality of education. To make this happen, the goal is to strengthen teachers' capacity in the basic education including administrators and non-teaching personnel; ensure a responsive and relevant curriculum; improve facilities of school through classroom construction; and prioritize on quality learning resources. However, the plan also mentioned that the achievement rates of elementary and secondary students remained low which implies low education quality and making the aim to raise the quality of education a constant challenge due to the condition such as inadequate competencies of teachers, student-teacher ratios that are high, missing educational facilities that are basic, and the conditions of classroom quality (National Economic and Development Authority, 2017). This development plan was established before the COVID-19 pandemic which implies that there is a need to re-strategize and innovate further means in achieving better quality of education in the Philippines.

The Philippines in fact is one of the Asian countries that is hardly affected by the COVID-19 pandemic. Before the crisis, it has been an issue on how the education system in the Philippines could be improved in the recent years. Accordingly, the Philippine Statistics Authority (PSA) as reported by San Buenaventura (2019), education facilities are upgraded with the following 2016 year data: 25.6 percent and 33.2 percent of elementary and secondary schools respectively from the Department of Education was granted with internet connection access for purposes of upgrading the pedagogy. With this data, they emphasized that the internet connection, computers, and electricity are still the improvement areas for infrastructure for quality and equality in education. This report implies that the work of teachers in facing the current crisis due to pandemic became more challenging especially in the remote areas of the country. Contrastingly, in other countries like in Norway, Bubb and Jones (2020) stressed in their study that home-schooling implementation due to the pandemic promoted more students' learning independently, creatively, progressively, and feed backing became more useful for school leaders in looking into the crisis as an opportunity for innovations. However, in an economically challenged country like in the Philippines, Alipio (2020) stressed that the sectors of the country with low income and in rural areas where there is an issue on learners' financial, operational, and internet connectivity must be addressed first before shifting to e-learning during the pandemic. Additionally, it was emphasized that there is a need to address first the students' digital skills by providing training programs. 
The onset of COVID-19 pandemic forced all education sectors to become more resilient in delivering better quality of education through synchronous and asynchronous activities during the pandemic even with less trainings and preparations. The data given by the National Economic and Development Authority (NEDA) gives us the glimpse that there are a lot of work to do in raising the quality of education even before the pandemic. In fact, multigrade teachers' undying situations of adjusting and complying with the Department of Education's (DepEd) protocols and requirements made a slow improvement of their teaching practices in pedagogy due to the limited allocation of budget in the multigrade schools as compared to the monograde (De Borja et al., 2020). Moreover, multigrade teachers are challenged pedagogically in terms of grade grouping and medium of instructions conflict, planning the lessons, unfocused instruction, insufficient materials for learners, lack of training for multigrade teaching, and the presence of perceiving the effectiveness of multigrade teaching negatively (Bongala et al., 2020). Teachers in the Philippines carry the burden of these challenges as they teach using modular approach in remote teaching especially in the provinces where connectivity on the internet is a problem.

Furthermore, teachers during the pandemic who are teaching in the remote area of the country might have other significant experiences in delivering modular approach to cater the needs of their learners. Though the study of Sadiq and Zamir (2014) emphasized the effectiveness of modular teaching, Tria (2020) reiterated that several recommended teaching approaches for the new normal in education have issues and problems that are present and need to be addressed. For this reason, this study sought to explore and describe the personal experiences and the conduct of learning assessments of multigrade teachers who are teaching in the remote area using modular approach during the pandemic. The result of the study might enable the basic education department to further examine the conditions of multigrade remote teaching during the crisis and eventually create programs and policies for the improvement of modular approach especially in the multigrade level of teaching.

\subsection{Purpose of the research}

The main purpose of the study is to describe the experiences of multigrade teachers and how they conduct learning assessments on modular teaching during the COVID-19 pandemic. Specifically, it sought to: A.) Describe multigrade teachers' conduct of modular teaching approach, learning assessments, and the materials they use in delivering remote teaching during the COVID-19 pandemic; B.) Determine the challenges of multigrade teachers in conducting modular teaching approach during the pandemic as they collaborate with the local government units; and C.) Explore the views of multigrade teachers in improving the distribution of learning materials and modules with their description of school heads' role in addressing their concerns in modular teaching during the pandemic.

\section{Methodology}

Qualitative research design particularly, illustrative case study was employed to attain the objectives of the study. Accordingly, this type of case study describes the involved people, the place where they are, and what they do. Furthermore, the phenomenon or situation, what is being experienced and why it is being experienced describes an illustrative case study to inform readers about the specific topic being studied (Hayes et al., 2015). The study constitutes three phases of research procedure summarized in the following processes:

\section{Phase 1: Preparation}

The researchers had colloquy in determining the educational research topic that is deemed significant during the time of pandemic. It is followed by the discussion on what particular objectives is suited to achieve the relevance and purpose of the research. Target participants were identified through suggestions and connections with the teachers involved in modular remote teaching followed by the formulation of guide questions for interview. The questions for the interview were content validated by an expert. The authors also secured the 
consent of the participants and was made clear to them that all information that will be gathered in the study will be treated with utmost confidentiality and that anytime they can withdraw their consent from participating in the study. The participants were informed also that they will be subjected to focus group discussions to gather the needed data together with sharing of their weekly diaries of their experiences in catering modular remote teaching.

\section{Phase 2: Collection of experiences and assessments of learning in modular remote teaching}

The mode of communication with the teacher-participants is through the "Facebook messenger". On a weekly basis, teachers shared their experiences in teachings, their reflections and challenges in delivering modular remote teaching. In addition, the YouTube vlogs and shared photos on how the teacher-participants go to school to teach and distribute modules are also included in the observation, recording and organization of their experiences. Virtual meetings through "Google Meet" were conducted to facilitate interviews through focus group discussions.

\section{Phase 3: Post data analysis}

The qualitative data gathered from the participants were analyzed through coding and thematizing of their views and experiences in catering modular remote teaching and learning assessments during the pandemic.

\subsection{Participants of the study}

Purposively, chosen participants consisted of five teachers who are teaching remotely in the mountainous province of Quezon. They are teaching in the adopted schools of the "LakbayLapis2019" a non-profit advocacy program.

\subsection{Research instruments}

In gathering data, diary of teachers served as the participants' weekly sharing of teaching experiences in delivering remote learning through Facebook messenger; vlogs and pictures showed the teachers' documentary videos on how they go to school in accomplishing their task as teachers; and interview notes served as a tool in gathering teachers' reflections and further experiences conducted through focus group discussions were employed in the study.

\subsection{Data analysis}

Data gathered from the study were analyzed using descriptive coding strategy of Miles et al. (2014) where short phrase or word is created to assign labels to data followed by indexing and categorizing the inventory of themes emerged from the data. Moreover, triangulation of gathered data from the diaries of participants in sharing their teaching experiences, analysis of vlogs and pictures of multigrade teachers, and transcription of interviews from the virtual focus group discussion were also utilized to establish the validity and reliability of data presented in the study.

\subsection{Ethical consideration}

The researchers sought the consent of the participants through an inform consent form stating the details of the study including how the data will be gathered through their approval. They were assured of the confidentiality of their identity as well as the data that will be gathered in the study. Furthermore, the participants' safety is prioritized and assured that no harm will be inflicted to them as they participate in the study and that they can freely withdraw their consent to participate anytime they prefer to do so. Conflict of interest is avoided in the whole study process. The research is not funded by any organizations and is purely conducted for the interest of promoting enhancement of education in the field of remote teaching in times of pandemic.

98 Consortia Academia Publishing (A partner of Network of Professional Researchers and Educators) 


\section{Results and Discussion}

\subsection{Customs in modular remote teaching during the pandemic}

An arduous path in going to school - Coming to school even before the pandemic has been a challenge to the multigrade teachers who caters remote teaching in their province. According to the participants, they stay in the school on a weekly basis due to the path they are dealing with in coming to school. During the pandemic, they go to school according to the schedule set by their immediate heads to address the needed task that they must accomplish for their remote teaching. The path in going to school is arduous due to the mountainous structure of the province. One of the ways in reaching the schools is through travelling with companions while walking the steep, narrow, and muddy routes. Some of the teachers has to traverse the rocky coastal areas during low tides in order to reach the school in shorter time. Vlogs and pictures of the teacher-participants showed a challenging and tiring climbing up and down careful manner in order not to hurt themselves in going to school. In this sense, the presence of COVID-19 pandemic crisis adds up to the challenge of multigrade teachers in delivering better quality of education.

The mode of remote teaching during the pandemic is modular. Though Toquero (2020) mentioned that the highlights of distance learning in delivering education during the pandemic is the integration of technology, this is not yet possible in the area due to the poor internet connectivity and that economic status of families implies impractical affordance of gadgets. For this reason, the Department of Education enforced modular teaching as one of the alternative modes in delivering lessons. However, there are some considerations for the multigrade teachers in catering modular teaching during the pandemic.

Scheduled distribution and retrieval of modules in school or drop points area - The pandemic crisis made the multigrade teachers to adjust with the current protocols of the government in the distribution of modules to the learners. Schools organized systems in going to their respective schools or designated areas in order to address parents' queries about the printed modules or learning materials. One of the respondents narrated the following:

"In our school since we are using printed modules, we distribute them every Monday together with mam and other colleagues. However, my schedule to distribute the module together with one teacher is on Friday. Also, retrieval of the module is also weekly. After the distribution, parents who have the capability to text or have gadgets will message us and ask about the printed module given to them. That's all for now. [Teacher 1- Virtual Interview - October 31, 2020]

The narration of one of the multigrade teachers was in accordance with the protocols set by the government of delivering education amidst the pandemic. However, they have to adjust with the situation of their learning community to deliver more efficient way of educating the children. This adjustment implies greater effort for the multigrade teachers to deliver lessons as compared before the pandemic knowing that arduous paths they take in reaching their schools. Though Tan-Choi et al. (2020) stressed that caregivers and parents has an essential role to make remote learning successful by giving them strong encouragements and guidance from the teacher, the burden of giving instructions to parents on how to do or teach the content of lesson in the module for their children does not assure quality education since the parents themselves lack education according to the multigrade teachers.

\subsection{Learning materials in modular remote teaching}

Video lessons, textbooks, and supplementary reading materials were made to combat the insufficient supply of learning materials and problematic internet access - The multigrade teachers' passion in teaching during the pandemic helped them to deliver the content of the lessons found in the module with more flexible 
ways. This includes the creation of video lessons, the utilization of textbooks, and provision of reading materials as supplements in understanding the lessons. This is done with the approval of their teacher-in-charge as head of their respective schools in order to reach out with the children with better delivery of the content of the lesson. However, there were some drawbacks that was narrated by one of the teacher-in-charge. She pointed out:

"In addition, I am delighted with Teacher 4 and the parents as well who has access to internet because she created her own video lesson showing actual teachings of the lesson. It was good however, only a few parents could be able to watch the video. On my part, as a Grade 1 and 2 teachers, of course I only utilize the module and did not anymore added materials because it is already full of activities and I told the parents to help their children to answer the modules but focus more on reading. So, I also give reading materials and instructed the parents to let their child read further.” [Teacher 2- Virtual Interview - October 31, 2020]

Obviously, teachers are full of spirit in imparting alternative resources to deliver better quality of learning to students. However, due to other factors like internet connectivity of parents, the smooth flow of learning is interrupted. Additionally, other teachers mentioned that they provided textbooks as an additional reference to augment explanations which is limited in the module. They also provided supplementary materials from the Division Office to reinforce reading, addition, and subtraction to Kinder, Grade 1, and Grade 2 learners. Furthermore, other sharing of teachers emphasized the use of group chats as the means of communication on the queries of parents about the content of the modules was also utilized. According to the teacher, she entertained the questions and provided some reading materials but was not sure if the materials reached other parents who doesn't have smart phones.

This current situation of the respondents corresponds with Glasgow City Region Education (2020) statement that internet connections and digital access are critical requirements in order have a smooth remote learning and that teachers must be practical in reaching students who are deprived of digital access. This implies that modular remote teaching in the community of the respondents needs greater support and guidance on digital access among teachers, parents, and learners due to some factors that needs to be considered such as economic status and strong internet connectivity in order to lessen face to face interactions among them in times of pandemic crisis.

\subsection{Challenges encountered}

There was an adversity in the module distribution, erroneous modules, loss of interests among students, and resistant parents in fulfilling roles as a support to their child's education - There are some sentiments shared by the multigrade teachers during their conduct of modular remote teaching. Since there is a system on the distribution and retrieval of modules, orientation to parents followed by the conduct of the "new normal" in teaching exposes the multigrade teachers to certain challenges. These challenges include the adversity in the distribution of modules, students who gave up in studying, and parents who are reluctant of their roles as the support to modular teaching. One of the teachers mentioned that the distribution of modules made her disappointed due to the failure of some parents to come and fetch the modules of their child due to rainy weather even if it is their scheduled date and time of distribution knowing the facts of the challenge in going to school. In addition, one of the teachers also stressed that the conceptual errors found in the modules made them to pull out the copy from the parents for corrections and this requires doubling of effort from the side of the teachers.

Furthermore, some student loss their interest to study because of the challenge of the new normal which made them to decide not to continue their studies within the first months of the school year. The teacher narrates:

"In the beginning, I was very eager to organize the module and prepare what is needed, I chat the parents and monitor the students through text since I have two cellphones. I chat one parent and the other through text messages. After a week, during the distribution of modules, one parent told me that their child doesn't want to pursue studying because the child is having difficulty. So, 
I felt bad because it's just only a week and their child was already disheartened. The parent continued to tell me that they cannot force their child to study if the child doesn't want to. I suspected that since the parent is also having difficulty, it is okay not to encourage their child. So, I also told the parents to help their child, they can ask help from their neighbors who are knowledgeable, or they could always ask someone even the teacher." [Teacher 3 - Virtual Interview - October 31, 2020]

This scenario depicts the problem in the participation of the parents as the guide and support for their child's learning due to the educational capacity of the parents. Furthermore, other teachers affirmed this because the parents in their community also lacks education and they cannot give full attention in teaching their child since they are also working parents. Accordingly, the parents were very resistant of their roles as the support to their child's education during their meeting with the parents. This further escalated the challenges of teachers in motivating and encouraging the parents to be part of the learning of their children. In fact, according to the teachers, the new normal is that they do not teach the students, instead the parents are being taught by the teachers and then the parents will teach their child. They further mentioned that this is problematic since the parents did not also finish their studies so most of them cannot grasp the concept taught to them in the tutorial sessions conducted by the teachers.

Moreover, the parents would go back to school asking again the teachers for the concepts and skills they forgot especially in Mathematics subject. Even if the teacher wanted to conduct home visits, it is not possible and it is prohibited due to the pandemic. Contrastingly, this situation defeats the Department of Education Undersecretary statement that parents during this time of pandemic crises are partners of teachers in continuing to teach skills in problem-solving while at home (Capulso, 2020). This situation implies that the students in remote areas are not properly given equal opportunity of learning and likewise, the multigrade teachers in the community could have been exerting more effort in delivering the content of the lesson since parents' lapses due to their educational attainment defeats the purpose of remote learning. Additionally, the lack of digital access and internet connection in the area worsen the condition of teachers in accessing and delivering learning resources for better learning outcomes of the learners.

\subsection{The role of local government units}

The support of local government units is significant but limited in the distribution of modules - The local government units during the COVID-19 pandemic are supportive according to the multigrade teachers in terms of the distribution of learning materials in their community. The multigrade teachers attended barangay meetings in the planning of the distribution of the modules. Also, the barangay officials provided the teachers with boxes of coupon bonds, but the quantity is according to the population of students per school. Moreover, one of the teachers stressed that they are in doubt of the sustainability of the support of the local government officials because the agreement of bringing the modules in their office for them to distribute to the parents was not regularly done, instead the teachers ended in going to school for the module distribution. However, in other barangays, full support of officials was evident. According to the teacher:

'Sir, in our local government unit they gave us bond paper, but it depends on the number of populations. Since our school is small, we only received two boxes of bond paper. In the distribution of modules, we tapped our barangay officials and asked them to make their offices to be the drop points. They agreed that we will just bring the printed modules and they will be the ones to distribute it. However, as the opening of classes is approaching, we decided that we should be the one to distribute the modules because we anticipated that they might just be eager only for now and then in the end there might be problems. So, the parents are already going to the school to pick up the modules instead of the original plan of going to the barangay. The barangay officials is still willing to help. Thank you!" [Teacher 4 - Virtual Interview - October 31, 2020] 
These instances proved the important role of local government units as the support in the multigrade teachers' task of module distribution in the remote learning. In fact, the local government units did not fail to grant the appeal of the Department of Education Secretary of their support for the Learning Continuity Program of the department (Malipot, 2020). This implies that the national government should further strengthen the support for the local government units in performing their roles in the education sector during the pandemic.

\subsection{Multigrade teachers' views in improving modular remote teaching}

Quality assured modules - Modular approach was deemed appropriate in the time of pandemic crisis especially in areas where digital access is a challenge to teachers. However, there were some lapses of the modular approach that was mentioned by the participants. First, the self-learning materials (SLMs) particularly the module must be distributed to the parents before the classes open according to the report of Magsambol (2020). However, one of the multigrade teachers suggested that supply of modules should be ready ahead of time. This implies that there is a delay in receiving the copies of the modules on the part of the teachers. Second, other teachers emphasized there are conceptual errors that need to be corrected even if the modules have already been distributed to the parents. Hence, the retrieval to correct the modules exposes the teachers to more face-to-face interactions with the parents. Accordingly, if the multigrade teachers have problem like this, they collaborate with one another and they solve the problem among them. Third, the quality of prints was pointed out by one of the teachers. Some modules were printed with colors while in other schools was printed in black and white. One of the teachers narrated:

"In terms of module, when I compare it with others, their module has black marks printed like in a photocopy prints, so it appears with dark shades that makes it unclear. Compared to our module, it is beautiful, when you open it, it appears original, we have lots of ink." [Teacher 1Virtual Interview - October 31, 2020]

This instance implies that printing of modules is not standardized across the regions of the country. Notably, appropriation of funding for modules needs to be reassessed. Reports of Mateo (2020) emphasized that in the school year 2020-2021, the Department of Education has allotted nine billion pesos for printing of modules. This is a clear indication that printing of modules is not standardized according to a fair budget allotment that have resulted to a non-quality prints of self-learning materials in some areas of the Philippines.

More financial support to modular remote teaching - Education budget is vital to ensure better quality and delivery of education in a country. However, in the Philippines, Durban and Catalan (2012) stressed that the government doesn't give much budget in the Philippine education system especially in the rural areas resulting to poor and late delivery of school facilities. Although the report of the Department of Budget and Management (2019) emphasized that Education Departments in the Philippines already received the highest budget allocation in the current administration, the Department of Education's 536.1-billion-peso allotment for basic educational facilities program implementation, teaching and non-teaching position creations, and educational assistance provision; still teachers in the remote areas of the country need more budget support for their respective communities. In fact, one of the multigrade teachers shared the following sentiments:

"In my case, not from the school but a support coming from others. For example, from the DepEd. Since we have already said that we solved our own problem among with our colleagues to make our work easier in our school, DepEd should consider giving further support for the teacher. I think they consider more, I'm not sure for the reason is that they give more support for teachers coming from the big schools. In reality, even if we teach in a small school or small barangay, we also need more support since most people in our community doesn't have formal education or did not finish their education. For this reason, parents here prioritize working rather than giving attention or support to their child's schooling. So, teachers here need more support especially those who are coming from far places in going to school. In this time, it is not 
Multigrade teachers' experiences and learning assessments on modular remote teaching during COVID-19

easy to teach or have tutor for the children. The teachers also need some little. how do I call it

mam? Compensation." [Teacher 2 - Virtual Interview - October 31, 2020]

This is a clear indication that even though the education section received the highest allocation of budget, still is not enough to compensate teachers' effort who are teaching remotely especially in this time of pandemic. Additionally, these multigrade teachers experienced weather problems, power interruptions, and must consider conditions of the sea in going to their respective areas of their community to distribute modules. Moreover, to give extra activities for their students, teacher-respondents mentioned that they print the extra activity sheets. This implies the teachers could have use their own resources coming from their own pockets. This is not a new issue on the part of teachers in the Philippines spending their own money for the sake of their students. For instance, in the study of Quejada and Orale (2018), they emphasized that in order for the teachers to facilitate learning who are teaching in the far-flung areas in Samar, Philippines, they have to spend an amount coming from their own salaries in buying school supplies and materials to be used in their classroom and the teachers commonly provide the students with money for food and school supplies. This is an implication that teachers' compensation specifically in the remote areas of the Philippines should be addressed in the allocation of school budget especially in this time of pandemic crisis.

\subsection{The role of school heads in the modular remote teaching}

Teacher-in-charge as the School Head - The remote schools are usually considered as small schools. The schools of the multigrade teachers consist of three to five teachers including the teacher-in-charge who performs the job of a school principal. Notably, teacher-in-charge also performs the job of regular teachers and thus, also experienced regular challenges in going to school and in the distribution of modules aside from their work description as the school principal. Accordingly, the teacher-in-charge wanted also to be reclassified as school principal since they perform the job description of such position however, it is not possible since their school is composed only of four teachers including the teacher-in-charge. It is indicated in the DepEd order 97 series 2011 that one of the basic policies to be reclassified as school principal is to have at least nine teachers in the school where they teach (Department of Education, 2011). For this reason, the teacher-in-charge could not ask for reclassification to make their salary to at least increase despite of their dual work job performance. In fact, the multigrade teachers are in favor of the reclassification of their teacher-in-charge colleague since they know how hard their work is especially during the pandemic. As a confirmation, two of the respondents mentioned the following.

"In our case sir, I cannot do my job alone as the teacher-in-charge. My colleagues are really great. The four of us can be able to make our school function even in this time of pandemic. We work together for the students... So there is a need to increase the salary of teacher-in-charge...

[Teacher 1 and 2 -Virtual Interview - October 31, 2020]

The narration of the respondent implies on the sacrifice being done by the teacher-in-charge and at the same time a multigrade teacher when it comes to submission of reports as the school head. In fact, the teachers pointed out that when the teacher-in-charge are required to submit reports, they have to endure the risk of traversing the path going down the mountain or riding in boats alone in order to fulfill their call as the school head. This is an implication of professionalism they show in their field despites of the hardship they endure in fulfilling their task. Accordingly, Stone-Johnson and Weiner (2020) stressed that professionalism capacity of principals is critical in their work for the recognition of their decisions made in the level of district, state, and federal. In this time of pandemic, the commitment of teacher-in-charge in performing their job as multigrade teachers as well as school head in remote teaching is truly remarkable and essential in facilitating remote learning. However, it also implies reconsideration and re-evaluation of their benefits in performing dual jobs. 


\subsection{The conduct of learning assessments}

Multigrade teachers conduct of learning assessments is an intricate response to the encountered community situation to adhere with what the Department of Education requires - Amidst the COVID-19 pandemic, the Department of Education provided guidelines for assessment and grading as part of the learning continuity plan in the basic education stated in the DepEd order no. 31 series of 2020. Based on the multigrade teachers' experiences, they are adhering to the order despite of the pandemic situation. Remarkably, teachers' activities to assess students' learning involves variety of approach in addressing the challenges they encountered in the conduct of learning assessment.

The mode of multigrade teachers in giving feedbacks and assessments is through communicating with the parents when to retrieve the modules. During the retrieval, teachers find time to explain the lesson to the parents and the proper processes of answering the task in the module especially in Mathematics subject. Furthermore, notes are written in the module to show the correct answer to the students. The role of the parents after is to explain to their respective child. However, not all parents could be able to attend, respond, and cooperate with the approach due to the reason that they also need to make a living. So, the teachers try to communicate with the other parents through messaging but still parents could not reply because they don't have digital access. This implies that though teachers perform feedbacks and assessments, there are parents who are left behind in performing their roles as a support to the learning of their child.

In assessing the progress of students, teachers set up mechanisms to fulfill monitoring and recording. For instance, one teacher shared:

"What we did so far based on our LCP was to create a form which is given to the parents during module distribution where it is ready for parents' reflections by ticking off. Especially in my subject where I handle the primary, they really need the guidance of parents. It is indicated in the form, which subject for them they find easy and difficult so we can monitor what subject is difficult for the students for the week. Aside from that, we also use weekly home learning plan where we can check the designated activities that they need to accomplish, so the students can be able to see their progress of what they have or not answered. The students and the parents at least have participation in looking what have been accomplished. So, this is the new normal setting. We also have home visitations for selected students only because the houses are really far from each other in the mountains. So, the houses that are near to us can be easily visited but we usually target the far houses. So, the challenges that we encounter in this home visitation takes place because some parents really prioritize their work for living so even if they are only tasked to check the boxes corresponding to the progress of their child, they failed to do it. So those are the challenges we encounter." [Teacher 5 - Virtual interview - December 18, 2020]

The narration of the teacher implies that despite the effort conducted by the teachers to assess the learning progress, economic status of the community hinders the success of learning assessments. For this reason, other multigrade teachers encourage high school students in the community to have peer tutoring with the elementary students in exchange of small allowance for their schooling. This encouragement made the performance of students better and the parents were happy because they can be able to do their work while their children are progressing according to one of the teachers.

Furthermore, some teachers provide reading and writing materials as an additional asynchronous activity while other teachers did not accomplish designing more assessment materials because according to them, there are already many learning tasks in the module which were not answered by the students because they don't know how. Accordingly, adding more activities to the students might overwhelmed them of accomplishing too many task and teachers are avoiding that. In the end, teachers provided examples on the part of the module where students did not answer so they still have something to do at home once the teachers return to them unanswered 
part of the module.

In giving feedback and remediation to those students who are not performing well during the modular learning, other multigrade teachers who stays in school made themselves available to entertain parents' queries about the module even if the parents come in the afternoon and evening. Accordingly, teachers do this to assure that parents are relaying and teaching the correct concept in the module to their children since not all parents have formal education and then teachers follow it up with a summative test to let students have retention and assess what they have learned. Lastly, teachers emphasized that resources for assessment is quite challenging since there is a poor internet access in the mountainous area. Significantly, teachers and parents experience poor signal and only few parents have digital access who are lucky enough to communicate with the teachers. It is implied that this situation makes communication for feedback, progress, and learning assessments challenging.

\section{Conclusion}

The outcomes of this study exposed the experiences of multigrade teachers as well as how they conduct learning assessments in performing modular remote teaching during the COVID-19 pandemic. Thus, the succeeding conclusions were deduced: the multigrade teachers conduct modular teaching by traversing arduous path in going to school and designated areas where modules are distributed and retrieved; video lessons, textbooks, and supplementary reading materials was made to combat the insufficient supply of learning materials and the problematic digital access in the modular remote teaching; and multigrade teachers intricately conduct learning assessments in response to the encountered challenges in the community to adhere with the Department of Education order. Furthermore, multigrade teachers experienced challenges in teaching during the pandemic such as the adversity to distribute modules on time, erroneous modules, loss of interest among students, and resistant parents as a support to their child's education due to their educational background and the need to earn living.

Additionally, the support of local government units is significant but limited in the distribution of modules to the parents. Moreover, the multigrade teachers' views in improving modular remote teaching includes quality assured modules and they are in favor to have more financial support in the modular remote teaching. The teacher-in-charge performs dual jobs: the job of a school principal and a multigrade teacher thus, adding extra responsibilities for their efforts during the modular remote teaching. The implication of the study encompasses the need for the education policy makers to address the challenges that are being experienced by the multigrade teachers who are teaching in the remote area. It encourages the policy makers to prioritize the provision of quality learning materials and other essential tools and resources of teachers in fulfilling their jobs in multigrade teaching.

\subsection{Recommendations}

Based on the conclusions drawn, the following suggestions are hereby presented: policy makers could reconsider the allocation of budgets for both the systems in modular remote teaching and for the benefits of the teachers, this is to complement the risk of accidents in going in and out of the school and the extra cost of some supplementary materials shouldered by the teachers; improvement in the quality of modules and worksheets, prompt arrival and distribution of materials for learning, and the giving of sufficient supply of learning references for remote teaching could be done for easier, innovative, and versatile teaching during the crisis in remote areas as well as for communication between teachers and parents for learning assessments during the pandemic; the assurance of the quality of learning materials given to the multigrade teachers could be prioritized to lessen the burden of retrieving the modules for corrections; there is a need to review on the roles of parents as well who lacks education in fulfilling their role as support to their child's learning and in their roles that they perform in feedbacking and learning assessments; strengthening further the participation and support of local government units in the modular remote teaching is highly recommended to facilitate better distribution and retrieval of learning materials; and there is a need to review on the teacher-in-charge's job description as well as 
Chan, J. R., Marasigan, A. C., \& Santander, N. T.

on their benefits and incentives in performing dual jobs. This study exposed salient details as to how multigrade teaching could be improved in one of the remote areas in the Philippines. For this reason, it is further recommended for future researchers to conduct more related study about multigrade teaching in other remote areas to highlight and illustrate the essential needs in enhancing remote teaching and to contribute to reducing learners who are left behind to quality education.

Acknowledgement - This research paper was presented at the International Graduate Teacher Education Summit 2021 (IGTES 2021) held on March 13-14, 2021.

\section{References}

Alipio, M. (2020). Education during COVID-19 era: Are learners in a less-economically developed country ready for e-learning? In $Z B W$-Leibniz Information Centre for Economics. https://doi.org/10.2139/ssrn.3586311

Bongala, J. V., Bobis, V. B., Castillo, J. P. R., \& Marasigan, A. C. (2020). Pedagogical strategies and challenges of multigrade schoolteachers in Albay, Philippines. International Journal of Comparative Education and Development, 22(4), 299-315. https://doi.org/10.1108/IJCED-06-2019-0037

Bubb, S., \& Jones, M. A. (2020). Learning from the COVID-19 home-schooling experience: Listening to pupils, parents/carers and teachers. Improving Schools, 23(3), 209-222. https://doi.org/10.1177/1365480220958797

Capulso, L. B. (2020, June 12). Braving the k-12 education in the Philippines amidst the COVID-19 pandemic. K12 Digest. https://www.k12digest.com/braving-the-k-12-education-in-the-philippines-amidst-the-COVID-19-pand $\underline{\text { emic/ }}$

De Borja, J. M. A, Sigua, E. M. S, \& Marasigan, A. C. (2020). Pedagogical practices of multigrade teachers in conducting science learning activities. IOER International Multidisciplinary Research Journal. 2(3), 219-228. https://doi.org/10.5281/zenodo.4097987

Department of Budget and Management. (2019). 2019 National budget: Building a bright future for the Philippines and its people. Budget Information and Training Service. https://www.dbm.gov.ph/images/pdffiles/2019-People\%27s-Budget-Quick-Glance_English-Version.pdf

Department of Education. (2011). Revised guidelines on the allocation and reclassification of school head positions (pp. 1-16). Department of Education. https://www.deped.gov.ph/wp-content/uploads/2011/12/DO_s2011_97.pdf

Durban, J. M., \& Catalan, R. D. (2012). Issues and concerns of Philippine education through the years. Asian Journal of Social Sciences and Humanities, 1(2), 61-69.

Glasgow City Region Education. (2020). Effective remote and digital learning. In West Partnership (Issue May). https://education.gov.scot/media/wk4b33oy/wp-effective-remote-and-digital-learning.pdf

Hayes, R., Kyer, B., \& Weber, E. (2015). The case study cookbook (pp. 1-27). https://web.wpi.edu/Pubs/E-project/Available/E-project-121615-164731/unrestricted/USPTO_Cookboo kFinal.pdf

Magsambol, B. (2020, September 22). Fast facts: Deped's modular learning. Rappler IQ. https://www.rappler.com/newsbreak/iq/things-to-know-deped-modular-learning

Malipot, M. H. (2020, June 16). DepEd taps LGUs for learning continuity initiatives. Manila Bulletin. https://mb.com.ph/2020/06/16/deped-taps-lgus-for-learning-continuity-initiatives/

Mateo, J. (2020, August 7). P9 billion allotted for printing of learning modules. Philstar Global. https://www.philstar.com/headlines/2020/08/07/2033444/p9-billion-allotted-printing-learning-modules

Miles, M. B., Huberman, A. M., \& Saldaña, J. (2014). Fundamentals of qualitative data analysis. In Qualitative Data Analysis: A Methods Sourcebook (3rd ed., pp. 69-100). Sage.

National Economic and Development Authority. (2017). Philippine development plan 2017-2022. National

106 Consortia Academia Publishing (A partner of Network of Professional Researchers and Educators) 
Economic and Development Authority.

Quejada, A. B., \& Orale, R. L. (2018). Lived experiences of elementary school teachers in a remote school in Samar, Philippines. Journal of Academic Research, 3(3), 1-13.

Sadiq, S., \& Zamir, S. (2014). Effectiveness of modular approach in teaching at university level. Journal of Education and Practice, 5(1), 103-110.

San Buenaventura, P. A. R. (2019, January 19). Education equality in the Philippines. Philippine Statistics Authority.

https://mospace.umsystem.edu/xmlui/bitstream/handle/10355/37579/research.pdf?sequence=2

Stone-Johnson, C., \& Miles Weiner, J. (2020). Principal professionalism in the time of COVID-19. Journal of Professional Capital and Community. 5(4/5), 367-374. https://doi.org/10.1108/JPCC-05-2020-0020

Tan-Choi, A., Tinio, V. L., Castillo-Canales, D., Lim, C. P., Modesto, J. G., \& Pouezevara, S. R. (2020). Teacher's guide for remote learning during school closures and beyond. Foundation for Information Technology Education and Development.

Toquero, C. M. (2020). Emergency remote education experiment amid COVID-19 pandemic in learning institutions in the Philippines. International Journal of Educational Research and Innovation, 15(July), 162-176. https://doi.org/10.46661/ijeri.5113

Tria, J. Z. (2020). The COVID-19 pandemic through the lens of education in the Philippines: The new normal. International Journal of Pedagogical Development and Lifelong Learning, 1(1), ep2001. https://doi.org/10.30935/ijpdl1/8311

UN. (2020). The sustainable development goals report 2020. In The Sustainable Development Goals Report 2020. https://www.pps.org/category/placemaking 
Chan, J. R., Marasigan, A. C., \& Santander, N. T.

108 Consortia Academia Publishing (A partner of Network of Professional Researchers and Educators) 